\title{
Germinação e vigor de sementes de Crataeva tapia L. em diferentes temperaturas e regimes de $l u z^{1}$
}

\author{
Germination and vigor of Crataeva tapia L. seeds in different temperatures and light \\ regimes
}

\author{
Evio Alves Galindo ${ }^{2 *}$, Edna Ursulino Alves ${ }^{3}$, Kelina Bernado Silva ${ }^{4}$, Leandra Matos Barrozo ${ }^{4}$ e Sueli da Silva \\ Santos Moura ${ }^{5}$
}

\begin{abstract}
Resumo - O comportamento germinativo das sementes de diferentes espécies varia em função da temperatura e luminosidade, o que pode fornecer informações de interesse biológico, ecológico e da tecnologia de sementes, pois muito pouco se conhece com relação às exigências de sementes de espécies tropicais quanto aos diversos fatores envolvidos na germinação. O trabalho foi realizado com o objetivo de avaliar o efeito de diferentes temperaturas e condições de luminosidade sobre a germinação e vigor das sementes de Crataeva tapia L. No Laboratório de Análise de Sementes (LAS), do Centro de Ciências Agrárias, da Universidade Federal da Paraíba (CCA - UFPB), em Areia - PB foram avaliadas a influência das temperaturas de $25^{\circ} \mathrm{C}$; $30{ }^{\circ} \mathrm{C}$ e $35^{\circ} \mathrm{C}$ constantes e $20-30{ }^{\circ} \mathrm{C}$ alternada, sob regimes de luz branca (sem papel celofane), verde (com papel celofane verde), vermelha (com papel celofane vermelho), vermelha-distante (com duas folhas de papel celofane vermelho intercaladas por duas folhas azuis) e ausência de luz (com plástico preto), adotando-se o delineamento inteiramente ao acaso, em esquema fatorial 4 x 5 (temperaturas e regimes de luz), em quatro repetições de 25 sementes cada. As características analisadas foram: porcentagem de germinação, primeira contagem de germinação, índice de velocidade de germinação, comprimento e massa seca das plântulas. A temperatura alternada de $20-30{ }^{\circ} \mathrm{C}$, seguida da temperatura constante de $30^{\circ} \mathrm{C}$, podem ser recomendadas para testes de germinação e vigor de sementes de $C$. tapia. As combinações de temperatura e regimes de luz influenciam o potencial germinativo e o vigor de sementes de Crataeva tapia L.
\end{abstract}

Palavras-chave - Trapiá. Fitocromo. Medicinal. Análise de sementes.

\begin{abstract}
The germination behavior of seeds of different species varies on function of the temperature and luminosity, which can provide information of biological and ecological interest, and technology of seeds, because very little is known with respect to the requirements of seeds of tropical species as the various factors involved in germination. Therefore, the work was carried out with the objective of evaluating the effect of different temperatures and light conditions on germination and vigor of Crataeva tapia L. seed. In the Laboratory of Seed Analysis, in the Centro de Ciências Agrárias, Universidade Federal da Paraíba, located in Areia city - PB, were evaluated the influence of temperatures of $25{ }^{\circ} \mathrm{C} ; 30{ }^{\circ} \mathrm{C}$ and $35{ }^{\circ} \mathrm{C}$ constant and 20 $30{ }^{\circ} \mathrm{C}$ alternated under white light (without cellophane paper), green (with green cellophane paper), red (with red cellophane paper), far-red (with two sheets red cellophane paper interspersed for two sheets blue) and darkness (with black plastic), adopting a design entirely randomized with treatments distributed on factorial 4 x 5 (temperatures and light regimes), in four replications of 25 seeds each. Characteristics analyzed: germination percentage, germination first count and germination speed index, as well as the length and dry mass of seedlings. The seeds germinated in all light regimes, being recommended that on temperature of $20-30{ }^{\circ} \mathrm{C}$ alternate, and on temperature of $30^{\circ} \mathrm{C}$. Seeds of species studied are not sensitive to different light regimes applied under different temperatures.
\end{abstract}

Key words - Trapiá. Phytochrome. Medicinal. Seed analysis.

\footnotetext{
* Autor para correspondência

'Recebido para publicação em 03/11/2010; aprovado em 07/06/2011

Parte da dissertação de Mestrado do primeiro autor, apresentada ao Programa de Pós-Graduação em Agronomia/PPGA-CCA/UFPB

2Programa de Pós-Graduação em Agronomia/CCA-UFPB, Areia-PB, Brasil, eviogalindoea@hotmail.com

32 Departamento Fitotecnia e Ciências Ambientais/CCA-UFPB, Campus II, Areia-PB, Brasil, ednaursulino@cca.ufpb.br

${ }^{4}$ Programa de Pós-Graduação em Agronomia, Universidade Federal da Paraíba, Areia-PB, Brasil, kelinabernado@yahoo.com.br, leandrabarrozo@hotmail.com

${ }^{5}$ Graduando do Curso de Agronomia Universidade Federal da Paraíba, Areia-PB, Brasil, suelidasilvasantos@yahoo.com.br
} 


\section{Introdução}

Crataeva tapia L. é uma planta da família Capparidaceae, sendo chamada popularmente de cabaceira, cabaceira do pantanal, porém é mais conhecida como trapiá. Suas sementes são oleaginosas, de cor marrom clara, medindo cerca de $1 \mathrm{~cm}$. A árvore é dotada de uma copa arredondada e densa, sendo recomendada para a arborização e recomposição de áreas degradadas, cuja madeira é empregada para obras internas em construção, forros, caixotaria e confecção de canoas, e na medicina popular as cascas são usadas como tônico, estomáquico, antidisentérico, febrífugo e o fruto no combate às infecções do trato respiratório (LORENZI, 2002).

Em ambientes naturais as sementes podem ser encontradas sob diferentes regimes de luz e de temperatura, as quais podem variar de acordo com a estrutura do dossel (LINDIG-CISNEIROS; ZEDLER, 2001). Assim, o conhecimento do comportamentogerminativo das sementes é fundamental para a utilização de espécies florestais nativas na restauração de áreas degradadas, de forma que constitui providência essencial para proteger as espécies contra a ameaça de extinção (LABOURIAU, 1983), para a recomposição da paisagem (ARAÚJO NETO et al., 2003) e para a conservação da biodiversidade (CABRAL et al., 2003). Dessa forma, o entendimento do comportamento das sementes é de fundamental importância, pois várias destas espécies nativas são potencialmente utilizadas para essas finalidades (GOMES; FERNANDES, 2002).

A germinação é afetada por fatores internos e externos. Os internos são os intrínsecos da semente, como longevidade e viabilidade; já os fatores externos dizem respeito às condições ambientais. A temperatura, juntamente com a água e o oxigênio constituem os principais fatores externos que influenciam na germinação de uma semente (CARVALHO; NAKAGAWA, 2000).

Para os fatores temperatura e luz podem ocorrer interações, de forma que Labouriau (1983) relatou que a presença de luz, para muitas espécies, favorece a germinação das sementes, designando-se esse efeito como fotoblástico positivo; em outras espécies, o comportamento germinativo das sementes é melhor na ausência do que na presença de luz, o que se designa como fotoblastismo negativo.

As sementes expressam capacidade germinativa em limites bem definidos de temperatura, característicos para cada espécie (BEWLEY; BLACK, 1994). A temperatura ótima propicia uma porcentagem de germinação máxima em menor espaço de tempo, enquanto as temperaturas máxima e mínima são pontos em que as sementes germinam muito pouco ou não germinam (MAYER; POLJAKOFF-MAYBER, 1989).
A resposta à luz está associada ao fitocromo, que é o pigmento receptor responsável pela captação de sinais luminosos que podem ou não desencadear a germinação das sementes, de forma que a ação desse pigmento depende do tipo de radiação incidente (VÁZQUEZ-YANES; OROZCO-SEGOVIA, 1990).

A luz não constituiu um fator limitante na germinação de sementes de Leucaena leucocephala (Lam.) de Wit, uma vez que as mesmas germinaram na presença e ausência de luz (SOUZA FILHO, 2000). As sementes de Aspidosperma polyneuron. M. Arg. germinaram nos regimes de luz branca e vermelhadistante, sob as temperaturas constantes de 25 e $30^{\circ} \mathrm{C}$ e alternada de $20-30{ }^{\circ} \mathrm{C}$ (SAKITA et al., 2007). Na faixa de 10 a $25^{\circ} \mathrm{C}$, as sementes de Plantago ovata Forsk. se comportaram como fotoblásticas neutras, enquanto a $30{ }^{\circ} \mathrm{C}$, como fotoblásticas positivas preferenciais (SOUSA et al., 2008).

Devido à importância da espécie e da carência de informações sobre a tecnologia de suas sementes, este trabalho foi realizado com o objetivo de avaliar a germinação e o vigor de sementes de Crataeva tapia em diferentes regimes de luz e temperatura.

\section{Material e métodos}

\section{Local do experimento}

O experimento foi conduzido no Laboratório de Análise de Sementes (LAS), pertencente ao Departamento de Fitotecnia e Ciências Ambientais, do Centro de Ciências Agrárias, da Universidade Federal da Paraíba (CCA UFPB), em Areia - PB.

\section{Colheita e beneficiamento das sementes}

As sementes de Crataeva tapia utilizadas foram obtidas de frutos maduros, caracterizados pela coloração amarelada, os quais foram colhidos de 11 plantas matrizes, localizadas em Remígio - PB, em abril de 2009. Após a colheita os frutos foram levados para o LAS, onde foram abertos para a retirada das sementes, que após passarem por um processo de fermentação por 48 horas para retirada do arilo e, após serem lavadas em água corrente foram colocadas para secar pelo mesmo período citado anteriormente, em condições de laboratório. Antes da instalação do experimento as sementes foram tratadas com o fungicida Captan ${ }^{\circledR}$ (Captana), na concentração de $240 \mathrm{~g} / 10.000 \mathrm{~kg}^{-1}$ de sementes, enquanto a água para umedecimento do substrato continha o bactericida nistatina, na concentração de $2 \mathrm{~mL}$ por litro de solução. 


\section{Temperaturas e luminosidade}

O teste foi realizado em câmaras de germinação do tipo B.O.D. contendo lâmpadas (4 x $20 \mathrm{~W})$ e ajustados às temperaturas constantes de $25 ; 30$ e $35^{\circ} \mathrm{C}$ e alternada de $20-30{ }^{\circ} \mathrm{C}$. Os regimes de luz estabelecidos na pesquisa foram luz branca, vermelha, vermelhadistante e verde, em regime de 8 horas com luz (período diurno) e 16 horas sem luz (período noturno) e escuro (ausência total de luz branca).

$\mathrm{Na}$ simulação das condições de luz foram confeccionados sacos com papel celofane, onde para a luz branca os rolos foram cobertos com duas folhas transparentes; para a luz vermelha os rolos foram cobertos com duas folhas vermelhas; para a luz vermelha-distante os rolos foram cobertos com duas folhas vermelhas, intercaladas com uma azul; para a cor verde os rolos foram cobertos com duas folhas verdes, enquanto que a ausência de luz foi obtida cobrindo-se os rolos com sacos plásticos pretos.

Teste de germinação - Para cada tratamento utilizaram-se 100 sementes, as quais foram divididas em quatro repetições com 25, sendo distribuídas sobre duas folhas de papel toalha, cobertas com uma terceira e organizadas em forma de rolo. O papel toalha foi umedecido com água destilada na quantidade equivalente a 3,0 vezes a massa do papel seco. As avaliações do número de sementes germinadas foram diárias sob luz verde de segurança (Labouriau; Costa, 1976), iniciando-se aos sete dias após a semeadura e finalizando aos 11 dias. Foram consideradas plântulas normais, aquelas que haviam emitido a raiz primária e o hipocótilo.

Primeira contagem de germinação - Foi efetuada em conjunto com o teste de geminação, computando-se a porcentagem de plântulas normais obtidas no sétimo dia após a semeadura.

Índice de velocidade de germinação (IVG) - Foi determinado mediante contagens diárias do número de sementes germinadas, no mesmo horário, dos sete aos 11 dias após a semeadura, cujo índice foi calculado de acordo com a equação 1, proposta por Maguire (1962).

$\mathrm{IVG}=\mathrm{G}_{1} / \mathrm{N}_{1}+\mathrm{G}_{2} / \mathrm{N}_{2}+\ldots \mathrm{G}_{\mathrm{n}} / \mathrm{N}_{\mathrm{n}}$

em que: $I V G=$ índice de velocidade de germinação, $G_{1}, G_{2}$ e $G n$ = número de plântulas computadas na primeira, segunda e última contagem; $\mathrm{N}_{1}, \mathrm{~N}_{2}$ e $\mathrm{Nn}=$ número de dias da semeadura à primeira, segunda e última contagem.

Comprimento de plântulas - Após a contagem final do teste de germinação, as plântulas normais de cada tratamento e repetição foram medidas, da raiz até a parte aérea, com auxílio de uma régua graduada em centímetros, sendo os resultados expressos em $\mathrm{cm}$ plântula ${ }^{-1}$.

Massa seca de plântulas - As mesmas plântulas da avaliação anterior foram colocadas em sacos de papel Kraft e levadas à estufa regulada a $65{ }^{\circ} \mathrm{C}$, até atingir peso constante (48 horas) e, decorrido esse período, as amostras foram pesadas em balança analítica com precisão de 0,001 g, sendo os resultados expressos em g plântula ${ }^{-1}$.

Delineamento experimental e análise estatística - O delineamento experimental utilizado foi inteiramente ao caso, com os tratamentos distribuídos em esquema fatorial 5 x 4 (regimes de luz e temperaturas), em quatro repetições de 25 sementes cada. Os dados obtidos foram submetidos à análise de variância pelo teste $\mathrm{F}$ e as médias comparadas pelo teste Scott-Knott, a 5\% de significância.

\section{Resultados e discussão}

Entre os regimes de luz e as temperaturas houve efeito significativo dos fatores isolados, assim como da interação, para todas as variáveis avaliadas (TAB. 1). Pelos resultados da Tabela 2, referentes à interação observou-se que as maiores porcentagens de germinação foram obtidas aos 11 dias após a semeadura na combinação entre as temperaturas de $20-30{ }^{\circ} \mathrm{C}$ e luz vermelha e branca, bem como a $30^{\circ} \mathrm{C}$ sob luz vermelho distante e escuro.

Com relação aos efeitos dos regimes de luz em cada temperatura verificou-se que na temperatura de $25^{\circ} \mathrm{C}$ as maiores porcentagens de germinação ocorreram sob regime de luz vermelha e escuro; na temperatura de $30{ }^{\circ} \mathrm{C}$ foi sob luz vermelha-distante e escuro, a $35^{\circ} \mathrm{C}$ as maiores porcentagens de germinação foram sob luz branca e escuro, enquanto na temperatura de $20-30{ }^{\circ} \mathrm{C}$ obtiveram-se os maiores porcentuais de germinação, quando as sementes foram submetidas à luz branca e vermelha, enquanto ocorreu a menor germinação no escuro contínuo (TAB. 2).

Na temperatura alternada de $20-30{ }^{\circ} \mathrm{C}$ constatouse o melhor desempenho das sementes de C. tapia, quando considerados os regimes de luz branca, verde ou vermelha e uso de temperaturas alternadas, por simularem o ambiente natural de florestas onde as flutuações de temperaturas ocorrem, principalmente, pela abertura de clareiras, estimulam a germinação de sementes de espécies pioneiras. 
Tabela 1 - Quadrados médios de germinação (GERM), primeira contagem(PC), índice de velocidade de germinação(IVG), comprimento de plântulas (CP) e massa seca de plântulas (MS) de Crataeva tapia L. submetidas a diferentes regimes de luz e temperaturas

\begin{tabular}{ccccccc}
\hline \multirow{2}{*}{ Fonte de variação } & \multirow{2}{*}{ GL } & \multicolumn{5}{c}{ Quadrados médios } \\
\cline { 3 - 7 } & & GERM & PC & IVG & CP & MS \\
\hline Temperatura (T) & 3 & $4575,546^{* *}$ & $12869,867^{* *}$ & $17,365^{* *}$ & $182,799^{* *}$ & $0,333^{* *}$ \\
Luz (L) & 4 & $428,844^{* *}$ & $132,456^{* *}$ & $0,178^{*}$ & $3,558^{* *}$ & $0,006^{* *}$ \\
T x L & 12 & $1036,035^{* *}$ & $724,690^{* *}$ & $1,635^{* *}$ & $3,140^{* *}$ & $0,014^{* *}$ \\
\hline Resíduo & 60 & 26,4625 & 24,675 & 0,069759 & 0,319653 & 0,000374 \\
\hline CV (\%) & & 6,58 & 16,92 & 12,17 & 7,53 & 7,17 \\
\hline
\end{tabular}

$* \mathrm{e}^{* *}=$ significativo a 5 e $1 \%$, respectivamente, pelo teste $\mathrm{F}$

Tabela 2 - Germinação (\%) de sementes de Crataeva tapia L. submetidas a diferentes regimes de luz e temperaturas

\begin{tabular}{ccccc}
\hline \multirow{2}{*}{ Regimes de luz } & \multicolumn{4}{c}{ Temperaturas $\left({ }^{\circ} \mathrm{C}\right)$} \\
\cline { 2 - 5 } & 25 & 30 & 35 & $20-30$ \\
\hline Branca & $42 \mathrm{cD}$ & $86 \mathrm{bB}$ & $5 \mathrm{aC}$ & $95 \mathrm{aA}$ \\
Verde & $75 \mathrm{bC}$ & $78 \mathrm{cB}$ & $58 \mathrm{bD}$ & $93 \mathrm{bA}$ \\
Vermelha & $87 \mathrm{aB}$ & $88 \mathrm{bB}$ & $52 \mathrm{cC}$ & $96 \mathrm{aA}$ \\
Vermelha-distante & $76 \mathrm{bB}$ & $94 \mathrm{aA}$ & $28 \mathrm{dC}$ & $92 \mathrm{bA}$ \\
Escuro & $86 \mathrm{aB}$ & $94 \mathrm{aA}$ & $81 \mathrm{aC}$ & $84 \mathrm{cB}$ \\
\hline
\end{tabular}

Médias seguidas de mesma letra minúscula na coluna e maiúscula na linha não diferem a 5\% pelo teste de Scott-Knott

Resultados semelhantes foram obtidos por Araújo Neto et al. (2002) quando observaram que o uso de temperaturas elevadas (entre 35 e $45{ }^{\circ} \mathrm{C}$ ) provocou redução na germinação de sementes de Guazuma ulmifolia Lam. No entanto, Menezes et al. (2004) constataram que os maiores porcentuais de germinação de sementes de Salvia splendens Sellow foram obtidos na temperatura de 20 e $25^{\circ} \mathrm{C}$, na luz vermelho-extrema.

De forma semelhante ao observado no presente trabalho, algumas sementes de espécies florestais são indiferentes ao regime de luz, a exemplo de Guatteria gomeziana A. St. - Hil (GONÇALVES et al., 2006), de Aspidosperma polyneuron Muell. Arg. (SAKITA et al., 2007), de Erythrina verna Velloso (DEMUNER et al., 2008).

Sementes de diversas espécies florestais têm sido indiferentes à luz, a exemplo de Bauhinia forficata Linck. (ROSA; FERREIRA, 2001), Myracrodruon urundeuva $\mathrm{Fr}$. All (SILVA et al., 2002), Gallesia integrifolia (Spreng.) Harms. (BARROS et al., 2005), Tabebuia serratifolia (Vahl.) Nich.), Tabebuia chrysotricha, Tabebuia roseo alba (SANTOS et al., 2005) e Caesalpinia peltophoroides Benth (FERRAZ-GRANDE; TAKAKI, 2006).
Na primeira contagem de germinação das sementes de C. tapia, realizada aos sete dias após a semeadura, verificou-se interação significativa, para regimes de luz e temperaturas. Os maiores porcentuais de germinação ocorreram na temperatura de $20-30{ }^{\circ} \mathrm{C}$ quando considerado o regime de luz branca, verde e vermelha. No escuro e no regime de luz vermelha distante, mereceu destaque a temperatura de $30{ }^{\circ} \mathrm{C}$ com maiores valores na primeira contagem de germinação (TAB. 3).

$\mathrm{O}$ teste de primeira contagem, indiretamente avalia a velocidade de germinação, pois a maior porcentagem de germinação na primeira contagem significa que umas sementes germinaram mais rapidamente que as demais (NAKAGAWA, 1999).

As variações de temperatura afetam a velocidade, a porcentagem e a uniformidade de germinação. Portanto, a temperatura ótima é aquela que possibilita a combinação mais eficiente entre a porcentagem e velocidade de germinação (MARCOS FILHO, 2005). Para sementes de dois lotes de Tabebuia impetiginosa (Martius ex A. P. de Candolle) Standley e $T$. serratifolia Vahl Nich. - Bignoniaceae a ausência ou presença de luz não influenciou no vigor determinado pela primeira contagem 
na temperatura de $30{ }^{\circ} \mathrm{C}$ (OLIVEIRA et al., 2005). Em sementes de Leucaena leucocephala Lam. o menor vigor, determinado pela primeira contagem de germinação ocorreu sob temperatura de $35{ }^{\circ} \mathrm{C}$ na ausência de luz (OLIVEIRA, 2008).

Os dados referentes ao índice de velocidade de germinação de sementes de C. tapia estão na Tabela 4. Verificou-se que na temperatura de $20-30{ }^{\circ} \mathrm{C}$ os maiores índices de velocidade de germinação ocorreram quando foram utilizados os regimes de luz branca, verde e vermelha. Na temperatura de $20-30{ }^{\circ} \mathrm{C}$ ou $30^{\circ} \mathrm{C}$ merece destaque a vermelha distante e na temperatura de $30^{\circ} \mathrm{C}$, destacou-se o escuro contínuo.

Para as sementes de Piminella anisum L., tanto na presença quanto na ausência de luz os maiores índices de velocidade de germinação ocorreram nas temperaturas de 20 e $25{ }^{\circ} \mathrm{C}$ (STEFANELLO, 2005). Para Solanum sessiliflorum Dunal a luz vermelha e vermelho-extrema na temperatura de $25{ }^{\circ} \mathrm{C}$ proporcionaram os maiores índices de velocidade de germinação (STEFANELLO et al., 2008).
O desenvolvimento inicial das plântulas de $C$. tapia avaliado pelo comprimento da parte aérea (TAB. 5), foi maior na combinação da temperatura de $30^{\circ} \mathrm{C}$, em regime de luz vermelha-distante e a $20-30{ }^{\circ} \mathrm{C}$ com o regime de luz branca. $\mathrm{Na}$ temperatura de $35^{\circ} \mathrm{C}$, independente do regime de luz avaliado, o desenvolvimento das plântulas não foi adequado, comprovando ser uma temperatura crítica para germinação das sementes desta espécie. Para os efeitos dos regimes de luz em cada temperatura verificou-se que os maiores comprimentos de plântulas foram atingidos quando as sementes foram submetidas à temperatura de $25^{\circ} \mathrm{C}$ sob luz vermelha-distante e vermelha, $30^{\circ} \mathrm{C}$ no regime de luz vermelha-distante, bem como a 35 e $20-30{ }^{\circ} \mathrm{C}$ sob luz branca.

A adaptação das espécies ao ambiente de ocorrência, se dá através do reflexo às temperaturas ocorrendo uma variabilidade de respostas conforme observado em plântulas de Anetum graveolens L. e Piminella anisum L. sendo obtidos os maiores comprimentos de plântulas a 20 e $25{ }^{\circ} \mathrm{C}$ sob regime de luz branca (STEFANELLO, 2005). Para Solanum sessiliflorum Dunal a luz vermelha e vermelhaextrema na temperatura de $25^{\circ} \mathrm{C}$ proporcionaram os maiores comprimentos de plântulas (STEFANELLO et al., 2008).

Tabela 3 - Primeira contagem de germinação (\%) de sementes de Crataeva tapia L. submetidas a diferentes regimes de luz e temperaturas

\begin{tabular}{ccccc}
\hline \multirow{2}{*}{ Regimes de luz } & \multicolumn{3}{c}{ Temperaturas $\left({ }^{\circ} \mathrm{C}\right)$} \\
\cline { 2 - 5 } & 25 & 30 & 35 & $20-30$ \\
\hline Branca & $0 \mathrm{cD}$ & $39 \mathrm{cB}$ & $16 \mathrm{aC}$ & $68 \mathrm{aA}$ \\
Verde & $1 \mathrm{cC}$ & $36 \mathrm{~dB}$ & $0 \mathrm{cC}$ & $64 \mathrm{bA}$ \\
Vermelha & $37 \mathrm{aB}$ & $28 \mathrm{eC}$ & $1 \mathrm{cD}$ & $52 \mathrm{dA}$ \\
Vermelha-distante & $16 \mathrm{bC}$ & $52 \mathrm{bA}$ & $0 \mathrm{cD}$ & $49 \mathrm{eB}$ \\
Escuro & $0 \mathrm{cD}$ & $66 \mathrm{aA}$ & $12 \mathrm{bC}$ & $55 \mathrm{cB}$ \\
\hline
\end{tabular}

Médias seguidas de mesma letra minúscula na coluna e maiúscula na linha não diferem a 5\% de significância pelo teste de Scott-Knott

Tabela 4 - Índice de velocidade de germinação (IVG) de sementes de Crataeva tapia L. submetidas a diferentes regimes de luz e temperaturas

\begin{tabular}{ccccc}
\hline \multirow{2}{*}{ Regimes de luz } & \multicolumn{4}{c}{ Temperaturas $\left({ }^{\circ} \mathrm{C}\right)$} \\
\cline { 2 - 5 } & 25 & 30 & 35 & $20-30$ \\
\hline Branca & $0,57 \mathrm{dD}$ & $2,80 \mathrm{bB}$ & $2,00 \mathrm{aC}$ & $3,16 \mathrm{aA}$ \\
Verde & $1,93 \mathrm{bC}$ & $2,68 \mathrm{cB}$ & $0,50 \mathrm{bD}$ & $3,10 \mathrm{aA}$ \\
Vermelha & $2,28 \mathrm{aC}$ & $2,66 \mathrm{cB}$ & $0,54 \mathrm{bD}$ & $3,12 \mathrm{aA}$ \\
Vermelha-distante & $2,27 \mathrm{aB}$ & $3,14 \mathrm{aA}$ & $0,49 \mathrm{cC}$ & $3,15 \mathrm{aA}$ \\
Escuro & $1,35 \mathrm{cD}$ & $3,09 \mathrm{aA}$ & $1,99 \mathrm{aC}$ & $2,74 \mathrm{bB}$ \\
\hline
\end{tabular}

Médias seguidas de mesma letra minúscula na coluna e maiúscula na linha não diferem a 5\% de significância pelo teste de Scott-Knott 
Tabela 5 - Comprimento de plântulas (cm) de Crataeva tapia L. oriundas de sementes submetidas a diferentes regimes de luz e temperaturas

\begin{tabular}{ccccc}
\hline \multirow{2}{*}{ Regimes de luz } & \multicolumn{4}{c}{ Temperaturas $\left({ }^{\circ} \mathrm{C}\right)$} \\
\cline { 2 - 5 } & 25 & 30 & 35 & $20-30$ \\
\hline Branca & $8,19 \mathrm{bC}$ & $9,66 \mathrm{bB}$ & $4,03 \mathrm{aD}$ & $10,69 \mathrm{aA}$ \\
Verde & $8,23 \mathrm{bC}$ & $9,38 \mathrm{bA}$ & $3,41 \mathrm{bD}$ & $8,88 \mathrm{bA}$ \\
Vermelha & $8,88 \mathrm{aD}$ & $9,91 \mathrm{bA}$ & $2,64 \mathrm{dC}$ & $7,36 \mathrm{dC}$ \\
Vermelha-distante & $9,27 \mathrm{aB}$ & $11,38 \mathrm{aA}$ & $2,38 \mathrm{dD}$ & $8,17 \mathrm{cC}$ \\
Escuro & $7,61 \mathrm{cB}$ & $9,63 \mathrm{bA}$ & $3,04 \mathrm{cC}$ & $7,64 \mathrm{~dB}$ \\
\hline
\end{tabular}

Médias seguidas de mesma letra minúscula na coluna e maiúscula na linha não diferem a 5\% de significância pelo teste de Scott-Knott

O maior conteúdo de massa seca das plântulas de C. tapia foi encontrado naquelas oriundas das sementes submetidas à temperatura de $20-30{ }^{\circ} \mathrm{C}$ no regime de luz vermelha, bem como na temperatura de $30^{\circ} \mathrm{C}$ sob regime de luz vermelha-distante e escuro contínuo (TAB. 6). Considerando os efeitos dos tipos de luz em cada temperatura, quando as sementes foram submetidas às temperaturas de 25 e $20-30{ }^{\circ} \mathrm{C}$ e luz vermelha, a $30{ }^{\circ} \mathrm{C}$ sob luz vermelha-distante e escuro, assim como na temperatura de $35{ }^{\circ} \mathrm{C}$ no escuro (TAB. 5), originaram plântulas com maior massa seca.

Para sementes de Salvia splendens Sellow os maiores conteúdos de massa seca foram obtidos na temperatura $20^{\circ} \mathrm{C}$ sob regime de luz branca (MENEZES et al., 2004), no entanto, a luz não influenciou o conteúdo de massa seca de plântulas de Bowdichia virgilioides Kunth (ALBUQUERQUE; GUIMARÃES, 2007).

O maior conteúdo de massa seca obtido nos tratamentos citados pode ser explicado pelo fornecimento das condições necessárias à germinação porque as sementes originam plântulas com maior taxa de crescimento, em função da maior capacidade de transformação e suprimento de reservas dos tecidos de armazenamento e maior incorporação destes pelo eixo embrionário (NAKAGAWA, 1999). Além disso, Vázquez-Yanes e Orozco-Segovia (1984) comentaram que as sementes aptas a responderem às flutuações térmicas possuem mecanismos enzimáticos que funcionam a diferentes temperaturas, de maneira que a germinação é desencadeada apenas quando ocorre variação.

Tabela 6 - Massa seca de plântulas de sementes de Crataeva tapia L. oriundas de sementes submetidas a diferentes regimes de luz e temperaturas

\begin{tabular}{ccccc}
\hline \multirow{2}{*}{ Regimes de luz } & \multicolumn{4}{c}{ Temperaturas $\left({ }^{\circ} \mathrm{C}\right)$} \\
\cline { 2 - 5 } & 25 & 30 & 35 & $20-30$ \\
\hline Branca & $0,119 \mathrm{cC}$ & $0,360 \mathrm{bA}$ & $0,151 \mathrm{bB}$ & $0,372 \mathrm{cA}$ \\
Verde & $0,234 \mathrm{bC}$ & $0,358 \mathrm{bB}$ & $0,085 \mathrm{cD}$ & $0,387 \mathrm{bA}$ \\
Vermelha & $0,282 \mathrm{aC}$ & $0,358 \mathrm{bB}$ & $0,076 \mathrm{cD}$ & $0,443 \mathrm{aA}$ \\
Vermelha-distante & $0,224 \mathrm{bC}$ & $0,421 \mathrm{aA}$ & $0,034 \mathrm{dD}$ & $0,336 \mathrm{~dB}$ \\
Escuro & $0,222 \mathrm{bC}$ & $0,405 \mathrm{aA}$ & $0,216 \mathrm{aC}$ & $0,313 \mathrm{~dB}$ \\
\hline
\end{tabular}

Médias seguidas de mesma letra minúscula na coluna e maiúscula na linha não diferem a 5\% de significância pelo teste de Scott-Knott 


\section{Conclusões}

1. As combinações de temperatura e regimes de luz influenciam o potencial germinativo e o vigor de sementes de Crataeva tapia L;

2. A temperatura alternada de $20-30{ }^{\circ} \mathrm{C}$, seguida da temperatura constante $30{ }^{\circ} \mathrm{C}$, podem ser recomendadas para testes de germinação e vigor de sementes de C. tapia.

\section{Referências}

ALBUQUERQUE, K. S.; GUIMARAES, R. M. Comportamento fisiológico de sementes de Bowdichia virilioides Kunth. sob diferentes temperaturas e condições de luz. Cerne, v. 13, n. 01, p. $64-70,2007$.

ARAÚJO NETO, J. C.; AGUIAR, I. B.; FERREIRA, V. M. Efeito da temperatura e da luz na germinação de sementes de Acacia polyphylla DC. Revista Brasileira de Botânica, v. 26, n. 02 , p. 249-256, 2003.

ARAÚJO NETO, J. C. et al. Temperaturas cardinais e efeito da luz na germinação de sementes de mutamba. Revista Brasileira de Engenharia Agrícola e Ambiental, v. 06, n. 03, p. 460-465, 2002.

BARROS, S. S. U.; SILVA, A.; AGUIAR, I. B. Germinação de sementes de Gallesia integrifolia (Spreng.) Harms (paud'alho) sob diferentes condições de temperatura, luz e umidade do substrato. Revista Brasileira de Botânica, v. 28, n. 04, p. 727-733, 2005.

BEWLEY, J. D.; BLACK, M. Seeds: physiology of development and germination. New York: Plenum Press, 1994. 445 p.

CABRAL, E. L.; BARBOSA, D. C. A.; SIMABUKURO, E. A. Armazenamento e germinação de sementes de Tabebuia aurea (Manso) Benth. \& Hook. f. ex. S. Moore. Acta Botanica Brasilica, v. 17, n. 04, p. 609-617, 2003.

CARVALHO, N.M.; NAKAGAWA, J. Sementes: ciência, tecnologia e produção. 4.ed. Jaboticabal: FUNEP, 2000. 588p.

DEMUNER, V. G.; ADAMI, C. et al. Influência da luz e da temperatura na germinação de sementes de Erythrina verna (Leguminosae, Papilionoideae). Museu de Biologia Professor Mello Leitão, n. 24, p. 101-110, 2008.

FERRAZ-GRANDE, F. G. A.; TAKAKI, M. Efeitos da luz, temperatura e estresse de água na germinação de sementes de Caesalpinia peltophoroides Benth. (Caesalpinoideae). Bragantia, v. 65, n. 01, p. 37-42, 2006.

GOMES, V. FEMANDES, G. W. Germinação de sementes de Baccharis dracunculifolia (Asteraceae). Acta Botanica Brasilica, v. 16, n. 04, p. 421-427, 2002.

GONÇALVES, F. G.; GOMES, S. S.; GUILHERME, A. L. Efeito da luz na germinação de sementes de Guatteria gomeziana (Unonopsislindmanii R. E. FR.) Revista Científica Eletrônica de Engenharia Florestal, v. 04, n. 08, 2006.
LABOURIAU, L. G. A germinação de sementes. Washington: OEA. $1983.174 \mathrm{p}$.

LABOURIAU, L. G.; COSTA, J. A. F. Objetivos e instalações básicas de um laboratório de fisiologia vegetal. Rio de Janeiro: Academia Brasileira de Ciências, 1976. 59p.

LINDIG-CISNEIROS, R.; ZEDLER, J. Effects of light on seed germination in Aphalaris arundinaceae L. (reed canary grass). Plant Ecology, v. 155, n. 01, p. 75-78, 2001.

LORENZI, H. Árvores brasileiras: manual de identificação e cultivo de plantas arbóreas do Brasil. Nova Odessa: Plantarum, 2002. $368 \mathrm{p}$.

MAGUIRE, J. D. Speed of germination-aid in and evaluation for seedling emergence and vigour. Crop Science, v. 02, n. 02, p. 176-177, 1962.

MARCOS FILHO, J. Fisiologia de sementes de plantas cultivadas. Piracicaba: FEALQ, 2005. 495 p.

MAYER, A. M.; POLJAKOFF-MAYBER, A. The germination of seeds. 4. ed. Great Britain: Pergamon Press, 1989. 270 p.

MENEZES, N. L. et al. Germinação de sementes de Salvia splendens Sellow em diferentes temperaturas e qualidade de luz. Revista Brasileira de Sementes, v. 26, n. 01, p. 32-37, 2004.

NAKAGAWA, J. Testes de vigor baseados no desempenho das plântulas. In: KRZYZANOSWKI, F. C.; VIEIRA, R. D.; FRANÇA NETO, J. B. (Ed.). Vigor de sementes: conceitos e testes. Londrina: ABRATES, 1999. p. 2.1-2.24.

OLIVEIRA, A. B. Germinação de sementes de leucena (Leucaena leucocephala (Lam.) De Wit.), var. K-72. Revista de Biologia e Ciências da Terra, v. 08, n. 02, p. 166-172, 2008 .

OLIVEIRA, L. M. et al. Temperatura e regime de luzna germinação de sementes de Tabebuia impetiginosa (Martius ex A. P. de Candolle) Standley e $T$. serratifolia Vahl Nich. - Bignoniaceae. Ciência Agrotecnologia, v. 29, n. 03, p. 642-648, 2005.

ROSA, S. G. T.; FERREIRA, A. G. Germinação de sementes de plantas medicinais lenhosas. Acta Botanica Brasilica, v. 15, n. 02 , p. $147-154,2001$

SAKITA, A. E. N.; SILVA, A.; PAULA, R. C. Germinação de sementes de Aspidosperma polyneuron M. Arg. (peroba-rosa) sob diferentes condições de qualidades de luz e temperatura. Instituto Florestal Série Registros, n. 31, p. 203-207, 2007.

SANTOS, D. L. et al. Efeitos da luz e da temperatura na germinação de sementes de Tabebuia serratifolia (Vahl) Nich, Tabebuia chrysotricha (Mart. ex DC.) Standl. e Tabebuia roseo alba (Ridl) Sand - Bignoniaceae. Ciência Florestal, v. 15, n. 01, p. 87-92, 2005

SILVA, L. M. M. et al. Efeito da luz e da temperatura na germinação de sementes de aroeira (Myracrodruon urundeuva Allemão). Revista Árvore, v. 26, n. 06, p. 691-697, 2002.

SOUSA, M. P. et al. Germinação de sementes de Plantago ovata Forsk. (Plantaginaceae): temperatura e fotoblastismo. Revista Árvore, v. 32, n. 01, p. 51-57, 2008. 
SOUZA FILHO, A.P.S. Influência da temperatura, luz e estresses osmótico e salino na germinação de sementes de Leucaena leucocephala. Pasturas Tropicales, v.22, n.2, p.47-53, 2000.

STEFANELLO, R. Efeito da luz, temperatura e estresse hídrico no potencial fisiológico de sementes de anis, funcho e endro. 2005. 56 f. Dissertação (Mestrado em Produção Vegetal) - Universidade Federal de Santa Maria, Santa Maria.

STEFANELLO, S. et al. Germinação de sementes armazenadas de cubiu sob diferentes condições de luz. Scientia Agraria, v. 09, n. 03, p. 363-367, 2008.

VÁZQUEZ-YANES, C.; OROZCO-SEGOVIA, A. Fisiología ecológica de las semillas de árboles de la selva tropical: um reflejo de su ambiente. Ciencia, n. 35, p. 191-201, 1984.

VÁZQUEZ-YANES， C.; OROZCO-SEGOVIA, A. Ecological significance of light controlled seed germination in two contrasting tropical habitats. Oecologia, v. 83, n. 02, p. 171-175, 1990. 